\title{
$\bullet$ \\ IJCRR \\ Project-Based Learning, an Effective Tool for the Active Teaching-learning Method for First-year Medical Students
}

Section: Healthcare

ISI Impact Factor

(2019-20): 1.628

IC Value (2019): 90.81

$\operatorname{SJIF}(2020)=7.893$

cc) (i) (8)

Copyright@IJCRR

\section{Hitesh N. Shah'1, Dharmik S. Patel ${ }^{2}$, Mitul N. Chhatriwala ${ }^{3}$}

\begin{abstract}
'Professor and Head, Department of Biochemistry, Pramukhswami Medical College, Bhaikaka University, Karamsad 388325, Anand, Gujarat, India; ${ }^{2}$ Associate professor, Department of Biochemistry, Pramukhswami Medical College, Bhaikaka University, Karamsad 388325, Anand,

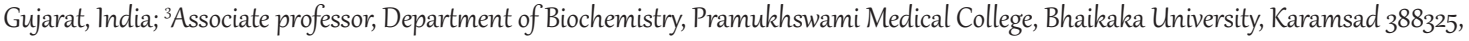
Anand, Gujarat, India.
\end{abstract}

\section{ABSTRACT}

Introduction: Poor attendances in classes especially in Biochemistry Subject and poor performances in PG entrance examination of students are a stimulus to think beyond the conventional teaching approach. There are different Teaching methods available today like Case-Based Learning, mini CEX (Clinical Evaluation Exercise), Project Base Learning, e-learning etc. ProjectBased Learning (PBL) focuses on imparting specific knowledge and skills while inspiring student to question actively and think critically.

Objective: To compare the effectiveness of Project-based learning with Case-based learning and didactic lectures.

Methods: Students of the 1st year MBBS from one private medical college were divided into 3 groups of 50 students each. Three groups were taught by Project-based learning, Case-based learning and the "chalk and board" method (didactic lecture) respectively. Three topics were selected so all three groups can be exposed by all teaching methods. After completion of these exercises, feedback was taken from all of the students. A post-test was conducted after each session and analysis was done.

Results: Out of 150 students 110 students gave their feedback and were actively involved in the study. Questions for feedback for all three-teaching methodology was made and the Likert scale was used for the evaluation. While analysing, the performance of students was in favour of project-based learning followed by case-based learning. The chalk and board method got very poor feedback and also bad performance in post-test evaluation.

Conclusion: Project-based learning was accepted by the students as an active learning method and feedback was reflected in the post-test evaluation. Students' Perception of the subject and attendance in the sessions can be improved by these methods.

Key Words: Innovative teaching, Project-based Learning, students' feedback, Teaching learning method, Didactic Lectures, Casebased learning

\section{INTRODUCTION}

Poor attendances in classes especially in Biochemistry Subject and poor performances in PG entrance examination of students are a stimulus to think beyond the conventional teaching approach. There are different types of teaching and learning methodologies are available in medical education. Nowadays medical education is also changing from traditional teaching to newer methods like CBL, mini CEX, Problem Base Learning, e-learning and so on. Project-Based Learning is an innovative, systematic teaching method that promotes student engagement through deep investigations of complex questions. Dur- ing teaching-learning activities, one would have come across one or more problem areas that are hurdles to the educational process. These problems may be unique to an educational set up and therefore may not have been addressed. Though concerted planned problem shooting and try out innovative methods which might circumvent constraints in the system.

A project work within reasonable limits may provide for independent and novel exploration based on an inquiry-driven approach. The educational project may involve inquiry into any of three aspects of the educational spiral to result in identification and solving problem in setting a clear objective, better

\section{Corresponding Author:}

Dr. Dharmik S. Patel, Associate Professor, Department of Biochemistry, Pramukhswami Medical College, Bhaikaka University, Karamsad 388325, Anand, Gujarat, India; Mob: +91 9978919892; Email: r.d.patelalways@gmail.com, dharmiksp@charutarhealth.org

ISSN: $2231-2196$ (Print)

Received: 09.10 .2020
ISSN: 0975-5241 (Online)

Revised: 26.11 .2020
Accepted: 09.01.2021
Published: 19.05 .2021 
teaching-learning experiences for the students and improved evaluation procedures.

A project plan would involve the development of a design, evolving a strategy of the procedures, putting them in to practice analysing and discussing outcome and improving the existing setup. Project-Based Learning is an effective teaching method, then traditional practices. An analysis conducted by Purdue University found that Project Based Learning can increase long-term retention of learning material and improve teachers' and students' attitudes toward learning. One explanation that researchers suggest is that both educators and learners are more actively engaged with the subject material. ${ }^{1}$

The experience of questioning, making mistakes, and pursuing inquiries in an organized, guided process makes PBL different from traditional teaching methods. As ArchF or Kids Co-Founder Karen Orloff explains, "From the first day of the project, the student becomes more receptive to challenges. They are more open to looking at mistakes as positive things as opposed to negative ones. ${ }^{2}$ Project-based learning activities should always culminate in a final product. There should be a sense of finality in the overall unit of study. Students need to be motivated to complete their work and to answer essential questions. Such experiences provide students with further instances of real-world applications of their work and prepare them for the demands of higher education and today's workplace. ${ }^{3}$ Research on Project-Based Learning can take several forms. ${ }^{4}$ Research can be undertaken to

(a) Make judgments about the effectiveness of PBL (summative evaluation),

(b) Assessor describe the degree of success associated with implementation or enactment of Project-Based Learning (formative evaluation),

(c) Assess the role of student characteristic factors in Project Base Learning effectiveness or appropriateness (aptitude-treatment interactions)

(d) Test some proposed feature or modification of ProjectBased Learning (intervention research).

There are different types of teaching and learning methodologies. Now MCI is also moving from traditional teaching to CBME. There are different methods available today like CBL, mini CEX, Problem Base Learning, e-learning and so on. In my opinion Project-Based Learning (PBL) is an innovative, systematic teaching method that promotes student engagement through deep investigations of complex questions. Project-based learning is not done with medical students and I do not have an idea but it is usually applied in other fields like engineering colleges. Put simply: 'It is learning by doing. This study was taken to assess the effectiveness of project-based learning tool over conventional teaching methods (chalk and board) in undergraduate 1st-year medical students.

\section{MATERIALS AND METHODS}

The study was conducted in a private medical college with a yearly admission capacity of 150 students. The study was conducted in the Department of Biochemistry with the involvement of three faculties. Students of 1st MBBS were divided into 3 groups of 50 students each. The project was allotted to one of the three groups with proper guidelines and instruction by faculties. The second group was taught by chalk and board \& the third group was taught by case base learning method. Liver function test, Thyroid function tests and Renal function test were the topic for the teaching. First, the Liver function test was taught to all three groups by method allotted, then the Renal function test was taught to all the three groups by teaching method allotted and then the Thyroid function test was taught to all three groups by method allotted. Ethical Permission was taken from the institutional ethical committee with permission letter no. IEC/ HMPCMCE/2017/Ex. 65

For each topic/method we did a rotation of faculties and students to remove selection bias and teacher bias. Two weeks was given for the preparation of the project for the given topic. At the end of the sessions, we took feedback and a post-session test through a short MCQ test. Timely feedback is taken. After completion of the project, submission of the project was done. Then feedback was taken from the students, a Post-test was conducted and analysis was done.

Step involved in project formulation: Identify a problem, Plan the project, Schedule, Monitoring and improvement, assessment and Evaluation. No additional burden was given to the students because it was done along with the normal day to day teaching schedule or activity. Teaching and project were done during the planned Biochemistry lecture and tutorial schedule. The project was approved by the institutional ethical committee.

\section{RESULTS}

The present study comprises 150 students and 3 faculty members. Out of 150 students, 110 students gave their feedback and were actively involved in the study. All the students were from 1st-year MBBS. Questions for feedback for all three-teaching methodology was used as per below and the Likert scale used for the evaluation:

Q1= It helps in developing communication skills among us

Q2= Student can learn the subject at his own pace

Q3= It enhances research aptitude

Q4= It gives opportunity to express creativity which develops more interest in the subject

$\mathrm{Q} 5=$ this allows you to work as a team 
Total 110 students gave their feedback for Project-based learning based on Likert's scale.

Statistically, a significant difference was found between posttest marks for all topics among the three groups. The group with project-based learning method performed very well compared to other teaching methods which were consistent for all teaching methods and students. One to one interview was done with involved faculties. All faculties were positive about project-based learning and future implementation in the routine curriculum.

\section{DISCUSSION}

In the current scenario of medical education, we are still using age-old teacher-centric teaching methods like didactic lectures and tutorials. We need to upgrade medical education from teacher-centric to student-centric methods like case-based learning, Project-based learning, problem-based learning, student seminars, role play etc. Up-gradation of teaching methodology needs time. We have tried to study project-based learning which is one of the student-centric and interactive methods. We have done feedback evaluation and MCQ evaluation for Case-based learning, Projectbased learning and Chalk \& board method and compared them with each other. We have tried to evaluate not only the subject knowledge but also tried to give more emphasis on other learning aspects like research aptitude, communication skills, inter person relation, creativity in subject and teamwork.

We have observed a significant difference in student feedback taken for all three different methods and three different topics. While analysing the feedback received from the students for project-based learning, we have found a significant difference between the three groups for all five feedback questions. Project-based learning emerged out as a winner when we analysed the MCQ score received after conducting the MCQ test for all three groups. Thomas et al. showed that project-based learning enhanced professionalism and collaboration on the part of teachers and increased attendance, self-reliance, and improved attitudes towards learning on the part of students. Similar to our observations, Thomas et al., reported that students and teachers both believe that Project Base Learning is useful and valuable as an instructional method. ${ }^{4}$ Although it is well-established that active learning provides significant practical and theoretical advantages over passive learning, teachers are often seen reluctant to employ these active learning strategies in routine teaching practice. $^{5}$

One Indian study, Patel et al also demonstrated that $76 \%$ of student participants liked Project-based learning compared to other methods. ${ }^{6}$ Very scanty reference is available on project-based learning in medical education. More researches in this field required to reach a definitive conclusion. Bédard et. al. considered project-based learning as innovative, especially from a student's perspective. ${ }^{7}$ Project-based learning strengthens the bond between student \& teacher. They learn empathy, passion, compassion, and resiliency. They push student's ability towards Self-directed learning.

\section{CONCLUSION}

In this $21^{\text {st }}$ century, e-learning is going to be the leading tool for medical education. Project-based learning leads to enhanced self-directed learning followed by increasing interest in the subject. The project given among the group leads to an increase in the ability to work as a team. Project-based learning build bonds between students and also improve bonding with teachers. Sometimes, Projects also develops research aptitudes among the students.

\section{ACKNOWLEDGEMENT}

I am grateful to undergraduate students and faculties of the institution of the Department of Biochemistry, as they have spare time for this project. The authors acknowledge the immense help received from the scholars whose articles are cited and included in references of this manuscript. The authors are also grateful to authors/editors/publishers of all those articles, journals and books from where the literature for this article has been reviewed and discussed.

Declarations: No funding was required for this project. IEC permission was taken before conducting this project.

\section{Conflicts of interest/Competing interests: No}

Authors' contributions: All authors have contributed to the project equally. In the formation of the protocol, IEC approval was taken by the $1^{\text {st }}$ author. Data collection and statistics has been done by all three authors. All three authors have given inputs in manuscript formation and worked hard for this study and its implementation in routine departmental practice.

\section{REFERENCES}

1. Blumenfeld PC, Soloway E, Marx RW, Krajcik JS, Guzdial M, Palincsar A. Motivating Project-Based Learning: Sustaining the Doing, Supporting the Learning. Educ Psychol 1991:26(3-4), 369-398.

2. Knoll, M. The project method: Its vocational education origin and international development. J Indus Teacher Educ 1997:34(3):59-80.

3. Polman JL. Designing Project-Based Science: Connecting Learners through Guided Inquiry. New York: Teachers College Press, Columbia University. 2000

4. Thomas JW. A Review of Project-Based Learning. A report prepared for The Autodesk Foundation. San Rafael, CA. 2000. https://www.bie.org/files/researchreviewPBL_1.pdf. 
5. Benek-Rivera J, Matthews VE. Active learning with jeopardy: Students ask the questions. J Manage Educ 2004; 28:104-18.

6. Patel JR, Patel DS, Desai R, Parmar J, Thaker R, Patel ND, et al. Evaluation of student seminar in medical education: students' perspective. Int J Curr Res Rev 2015;7(7):6-8
7. Bédard D, Lison C, Dalle D, Côté D, Boutin N. Problem-based and project-based learning in engineering and medicine: determinants of students' engagement and persistence. Interdisc J Problem-Based Learn 2012;6(2).

Table 1: Feedback of students for various aspects of Project based learning

\begin{tabular}{|c|c|c|c|c|c|c|}
\hline \multirow{2}{*}{$\begin{array}{l}\text { Sr. } \\
\text { No. }\end{array}$} & \multirow[t]{2}{*}{ Feedback Questions } & \multicolumn{5}{|c|}{ Frequency (Percentage) } \\
\hline & & $\begin{array}{l}\text { Strongly } \\
\text { Agree }\end{array}$ & Agree & Neutral & Disagree & $\begin{array}{l}\text { Strongly } \\
\text { Disagree }\end{array}$ \\
\hline 1 & Develop communication skills & $70(64)$ & $26(24)$ & $7(6)$ & $4(4)$ & $3(3)$ \\
\hline 2 & self- paced activity & $72(65)$ & $26(24)$ & $9(8)$ & $2(2)$ & $1(1)$ \\
\hline 3 & Enhances research aptitude & $62(56)$ & $18(16)$ & $6(5)$ & $11(10)$ & $13(12)$ \\
\hline 4 & $\begin{array}{l}\text { Develops more interest towards the } \\
\text { subject }\end{array}$ & $67(61)$ & $15(14)$ & $11(10)$ & $10(9)$ & $7(6)$ \\
\hline 5 & Team work & $69(63)$ & $12(11)$ & $17(15)$ & $6(5)$ & $6(5)$ \\
\hline
\end{tabular}

Liver Function Test: There are three Groups: [(Group A (PBL), Group B (CBL), Group C (BLACKBOARD)]. While analysing the post-test marks of the group $\mathrm{A}, \mathrm{B}$ and $\mathrm{C}$, the following observations were made.

Table 2: Post-test marks for Liver function test for all three groups

\begin{tabular}{llccccccc} 
BATCH.NO & & $\mathbf{Q}_{1}$ & $\mathbf{Q}_{2}$ & $\mathbf{Q}_{3}$ & $\mathbf{Q}_{4}$ & $\mathbf{Q}_{5}$ & Marks \\
Group A & Mean & 4.43 & 3.97 & 3.92 & 4.28 & 4.07 & 20.67 \\
& $\mathrm{~N}$ & 34 & 34 & 34 & 34 & 34 & 34 \\
\multirow{3}{*}{ Group B } & Std. Dev. & 0.59 & 0.81 & 0.83 & 0.94 & 1.26 & 4.43 \\
& Mean & 3.94 & 3.67 & 3.61 & 3.20 & 4.05 & 18.47 \\
& $\mathrm{~N}$ & 37 & 37 & 37 & 37 & 37 & 37 \\
Group C & Std. Dev. & 1.013 & 0.84 & 1.10 & 1.36 & 0.88 & 5.193 \\
& Mean & 3.16 & 3.27 & 1.86 & 2.75 & 2.70 & 13.74 \\
& N & 39 & 39 & 39 & 39 & 39 & 39 \\
& Std. Dev. & 1.30 & 1.14 & 1.10 & 1.03 & 1.41 & 5.98 \\
\hline
\end{tabular}

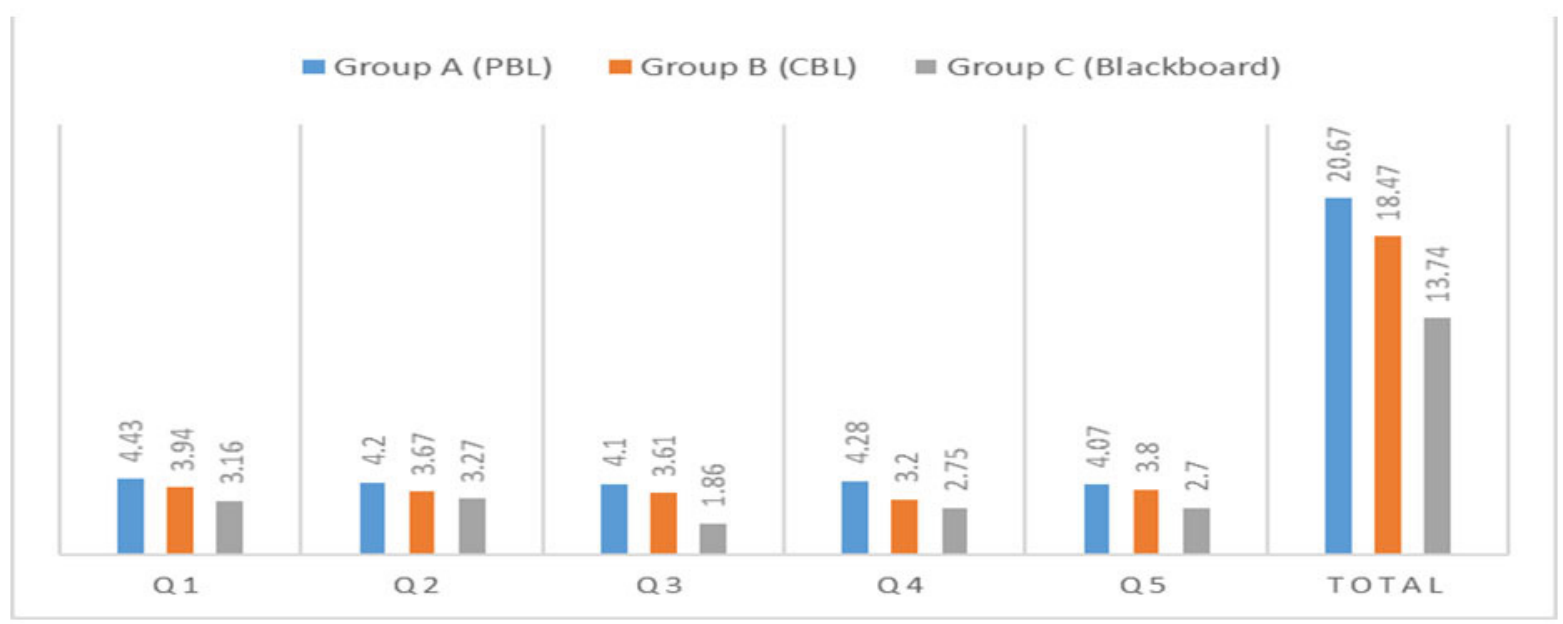

Figure 1: Comparison of post-test marks (LFT). Thyroid Function Test: There are three Groups: [(Group A (PBL), Group B (CBL), Group C (BLACKBOARD)]. While analysing the post test marks of the group A, B and C, the following observations were made. Students were rotated among the groups so they can be exposed to all teaching methods. 
Table 3: Post-test marks for Thyroid function test for all three groups

\begin{tabular}{llcccccc} 
BATCH NO & & Q1 & $\mathbf{Q}_{2}$ & $\mathbf{Q}_{3}$ & $\mathbf{Q}_{4}$ & $\mathbf{Q}_{5}$ & \multicolumn{2}{c}{ Marks } \\
Batch A & Mean & 4.43 & 4.1 & 3.92 & 4.38 & 4.2 & 21.03 \\
& N & 39 & 39 & 39 & 39 & 39 & 39 \\
\multirow{3}{*}{ Batch B } & Std. Deviation & 0.77 & 0.82 & 0.94 & 1.36 & 0.47 & 4.36 \\
& Mean & 4 & 3.73 & 3.88 & 3.2 & 4.2 & 19.01 \\
& N & 34 & 34 & 34 & 34 & 34 & 34 \\
\multirow{3}{*}{ Batch C } & Std. Deviation & 1.15 & 0.86 & 1.1 & 1.02 & 1.2 & 5.33 \\
& Mean & 3.35 & 3.56 & 2.32 & 3.18 & 3 & 15.41 \\
& N & 37 & 37 & 37 & 37 & 37 & 37 \\
& Std. Deviation & 0.59 & 0.85 & 0.83 & 0.74 & 1.03 & 4.04 \\
\hline
\end{tabular}

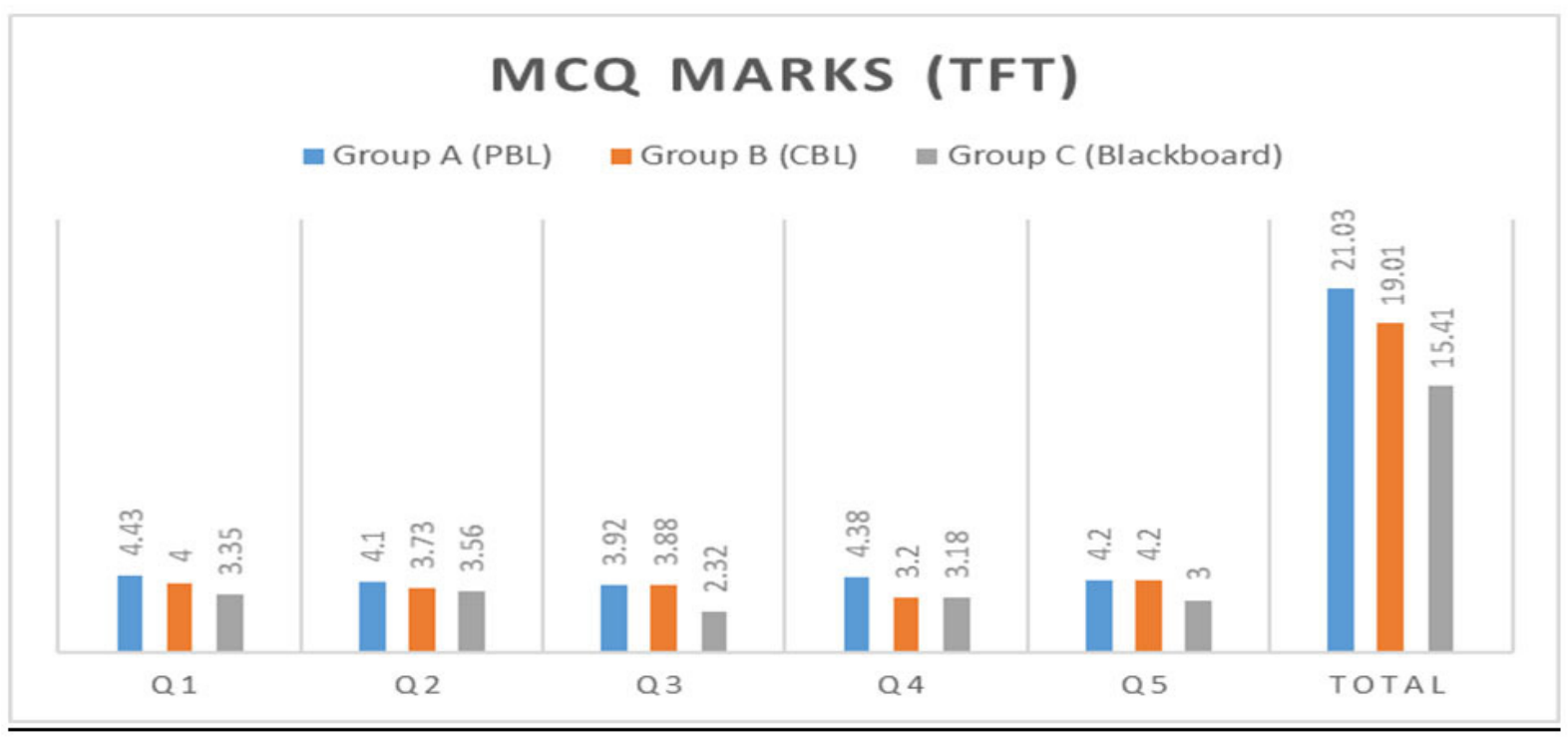

Figure 2: Comparison of post-test marks (TFT). Renal Function Test: There are three Groups: [(Group A (PBL), Group B (CBL), Group C (BLACKBOARD)]. While analysing the post-test marks of the group A, B and C, the following observations were made. Students were rotated among the groups so they can be exposed to all teaching methods.

Table 4: Post-test marks for Renal function test for all three groups

\begin{tabular}{llcccccc} 
BATCH NO & & Q1 & $\mathbf{Q}_{2}$ & $\mathbf{Q}_{3}$ & $\mathbf{Q}_{4}$ & $\mathbf{Q}_{5}$ & Marks \\
Batch A & Mean & 4.08 & 4.5 & 4.2 & 4.2 & 4.2 & 21.18 \\
& $\mathrm{~N}$ & 37 & 37 & 37 & 37 & 37 & 37 \\
\multirow{3}{*}{ Batch B } & Std. Deviation & 0.77 & 0.82 & 0.94 & 1.36 & 0.47 & 4.36 \\
& Mean & 3.8 & 3.76 & 3.3 & 3.88 & 3.8 & 18.54 \\
& N & 39 & 39 & 39 & 39 & 39 & 39 \\
\multirow{3}{*}{ Batch C } & Std. Deviation & 1.15 & 0.86 & 1.1 & 1.02 & 1.2 & 5.33 \\
& Mean & 2.98 & 2.32 & 3.5 & 2.9 & 3.1 & 14.8 \\
& N & 34 & 34 & 34 & 34 & 34 & 34 \\
& Std. Deviation & 0.59 & 0.85 & 0.83 & 0.74 & 1.03 & 4.04 \\
\hline
\end{tabular}




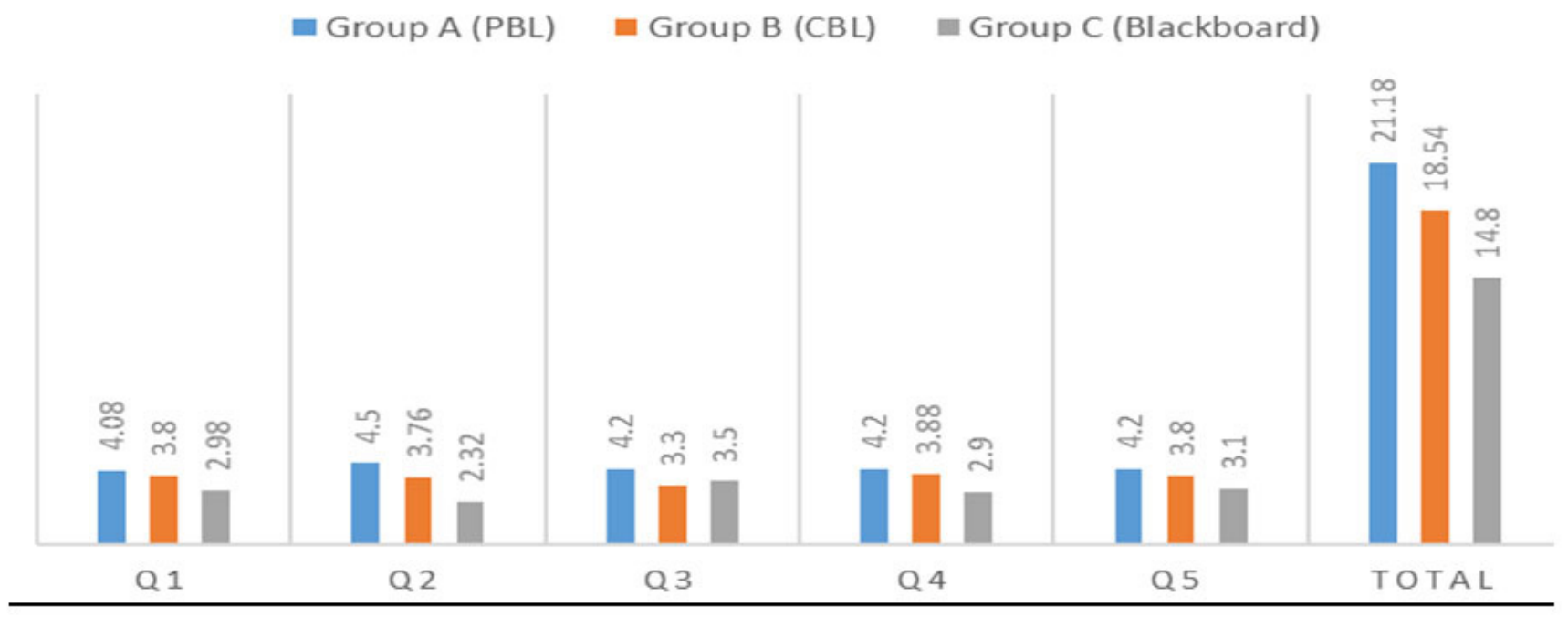

Figure 3: Comparison of post-test marks (RFT). 